\title{
Fiscal policy and growth forecasts in the EU: are official forecasters still misestimating fiscal multipliers?
}

\author{
David Cronin $^{1} \cdot$ Kieran McQuinn ${ }^{1}$
}

Accepted: 24 June 2021 / Published online: 7 July 2021

(c) Kiel Institute 2021

\begin{abstract}
Blanchard and Leigh (Am Econ Rev 103(3):117-120, 2013; IMF Econ Rev 62(2):179-212, 2014) find fiscal multipliers to be underestimated in the EU in the deep recession of the early 2010s. Using two 2013-2018 datasets for 26 EU member states, assembled from Stability and Convergence Programmes and the European Commission's Spring Forecasts, this paper shows that multiplier estimates in the EU have been overestimated in the post-crisis period. Forecasters then are still not capturing accurately the impact that fiscal policy has on output growth rates and are misestimating in a manner opposite to that reported by Blanchard and Leigh.
\end{abstract}

Keywords Fiscal policy $\cdot$ Multipliers $\cdot$ Forecast errors

JEL Classification C23 $\cdot$ E62 $\cdot$ H68

\section{Introduction}

The Blanchard and Leigh (hereafter BL) $(2013,2014)$ studies of the size of fiscal multipliers in European countries during the early 2010s prompted an intense debate among academics and policy makers concerning the effects of fiscal policy on output during a period of economic crisis. The empirical methodology of the BL contribution focussed on a regression of the forecast error in the output (GDP) growth rate on the planned fiscal consolidation of individual member states. Under rational expectations and assuming forecasters used the correct model for forecasting, the coefficient on the fiscal consolidation variable is expected to be zero. BL argued, however, that if forecasters underestimated the size of fiscal multipliers then there would be a negative and significant coefficient on the fiscal variable, which would explain the "growth disappointments" experienced by countries undertaking substantial fiscal retrenchment.

David Cronin

dave.cronin@centralbank.ie

1 Central Bank of Ireland, and Economic and Social Research Institute (ESRI), Dublin, Ireland 
Based on a sample of 26 European countries for the period 2010/2011, their baseline coefficient estimate on the fiscal consolidation variable was -1.1 . They employed a series of robustness tests, which backed up their central finding of a significant negative coefficient on the measure of consolidation. During the most severe of the European recession (2010 and 2011), therefore, BL interpret the true value of the multiplier as being about 1.6, that is the "normal times" multiplier of 0.5 plus the 1.1 value. Consequently, BL claim the substantial fiscal contraction of the period had a much more negative impact on output growth than was expected a priori. They also contend that the scale of their multiplier estimates could be conditional on the 2-year period over which they were estimated, one of deep recession in Europe.

As member states respond to the damaging economic effects of the COVID-19 pandemic through fiscal stimulus, and notwithstanding the state-dependency of multipliers, it is important to examine whether shortcomings arose with official forecasters' estimates of fiscal multipliers in the EU after the recession of the early $2010 \mathrm{~s}$ ended. ${ }^{1}$ If official multipliers are estimated inaccurately in what BL refer to as "normal times", and against the background of what has been learned from their assessment, then it suggests that it may be difficult to quantify the extent to which fiscal policy would address reduced demand in the economy arising from the effects of the pandemic. In this paper, we update then the BL analysis by applying their model to a sample of 26 EU member states over the period 2013-2018 using, in one dataset, the projections of ministries of finance (in their Stability and Convergence Programmes, henceforth SCPs) and, in a second dataset, those of the European Commission (in its Spring Forecasts). ${ }^{2}$ GDP outturn data are sourced from the EU AMECO database. Assessing the accuracy of fiscal multipliers for this period provides a timely insight into how efficiently fiscal policy may or may not be implemented presently.

The analysis is conducted over a period where changes to the EU fiscal rules enacted, in part, to support better macroeconomic and fiscal forecasting in the wake of the 2008-2012 financial and sovereign bond market crisis had taken effect. The European Semester was adopted in 2010 with the purpose of improving ex-ante economic and budgetary policies in the EU. Its introduction coincided with a new "six pack" (of five regulations and one directive) intended to strengthen the Stability and Growth Pact and its "preventive arm" geared to providing detailed scrutiny of member states' budgetary and macroeconomic forecasts. A concern that had been voiced in the policy literature was of a bias in official forecasts within Europe, with, for example, Jonung and Larch (2006), Frankel (2011), and Frankel and Schreger

\footnotetext{
1 The IMF (2020a) estimated in April 2020 that the fiscal cost of the healthcare response to the pandemic and tax and expenditure measures to support the economy would cost $€ 3.3$ trillion globally. Discretionary fiscal measures taken by EU member states amounted to 3.1 per cent of EU-27 GDP. The annex to the report notes the historically large spending and revenue measures being adopted by individual EU member states in response to the pandemic.

2 SCPs outline governments' economic outlook and fiscal policy over the medium term. They are submitted for peer review and assessment by the European Commission in April of each year. Consequently, we will be assessing how accurately member states adjudge the effects of discretionary fiscal policy on the output growth rates of their respective national economies. The Spring Forecasts of the European Commission can shed light on whether any errors in assessing the effect of fiscal policy on output by member states are shared by that institution.
} 
(2013) illustrating an "optimism bias" in official growth forecasts. In response to such academic studies and the experience of forecasting during the crisis (exemplified in BL's findings), the Fiscal Compact, effective since 2013, provided for independent oversight of member states' forecasting at the national level, including a role for independent forecasting authorities. BL also contend that official forecasts may improve due to learning, including from the 2010-2011 experience. This paper focuses then on the recent forecasting performance of member states and the European Commission against the background of the experience of the last economic crisis and where increased fiscal and forecasting oversight is in place at national and EU level.

Our findings indicate that official forecasters continue to miscalculate the size of fiscal multipliers. Unlike BL, however, we find that forecasters now overestimate the effect of fiscal policy on output growth, as opposed to underestimating it. Our econometric results hold irrespective of whether the forecasts used are those of the member states or of the European Commission and are robust to the inclusion of control variables. The concluding section of the paper discusses the policy implications, both in general and in the new economic circumstances arising from the Covid-19 epidemic, of these results.

\section{Methodology and data}

Since our panel dataset comprises yearly observations, we adapt BL's (2013) basic regression specification as follows ${ }^{3}$ :

$$
\text { Forecast Error of } \Delta Y_{i, t}=\alpha+\rho \Delta F_{i, t \mid t}+\varepsilon_{i, t}
$$

where $\Delta Y_{i, t}$ denotes the growth rate of real GDP (Y) in member state $i$ in year $t$ and the associated forecast error is $\Delta Y_{i, t}-f\left\{\Delta Y_{i, t} \mid \Omega_{t}\right\}$, with $f$ denoting the forecast contained in the member state's SCP (or the European Commission's Spring Forecast) for year $t$, which is conditional on $\Omega_{t}$, the information set available early in year $t$. The variable $\Delta F_{i, t \mid t}$ is the planned change in the General Government structural budget balance (SBB), measured as a percentage of potential GDP, in year $t$, as included in the SCP (or Spring Forecast) for that year. Under the null hypothesis that the ex-ante fiscal multipliers used for forecasting were accurate, the estimated $\rho$ should be zero. If the coefficient is significantly different from zero then forecasters are still misjudging fiscal multiplier values in the post-crisis era.

We estimate (1), and variants of it, using panels of yearly planned changes-inSBB, GDP growth rate forecast errors and other data collected for 26 member states between 2013 and 2018. GDP outturn data, needed for the calculation of the growth forecast error on the left-hand-side of (1), are from the EU AMECO database. The

\footnotetext{
3 Accordingly, we are assessing the size of a fiscal multiplier over the course of 1 year whereas BL estimate at a 2-year horizon. Fiscal multiplier values are expected to differ between different horizons (see Spilimbergo et al. (2009), for a review) but it is appropriate and instructive to consider errors in the a priori measurement of fiscal multipliers over any timespan.
} 
starting date of 2013 is appropriate with harmonised SBB data being available from that time and the post-crisis enhancement of the EU fiscal rules having been largely completed by then. Of the 28 EU member states, Greece did not provide SCPs in any of years from 2013 to 2018 and thus is not included in the dataset. The UK is excluded also as there are missing data in its SCPs and its budgetary year straddles calendar years. Of the remaining 26 member states, Cyprus only provided SCPs from 2016 to 2018 and Croatia for the years 2015 to 2018. A particular difficulty arises for Ireland and Malta for 2015. Both countries had extremely elevated output growth rates and, consequently large GDP forecast errors, in that year. Ireland had a real GDP growth rate outturn of 25.2\% in 2015 and Malta had a growth rate of $10.8 \%$. Such growth rates were linked to tax-related decisions of multi-national firms (see Christian Aid (2017) and FitzGerald (2018) for more on this). Consequently, given the extreme GDP growth forecast errors arising from these outturns, the observations for 2015 for Ireland and Malta are dropped from the data sample.

The baseline dataset then comprises 149 observations (i.e., $\mathrm{N}=149$ ). Scatter plots of both the SCP and Spring Forecast data are shown in the two panels of Fig. 1. The period was one where member states engaged in both fiscal consolidation, marked by positive values in the change in SBB, and loosening in fiscal policy, shown by negative values for the same variable. The fitted lines in both graphs suggest a positive relationship arising between the change in the SBB and the GDP growth rate forecast error. The next section provides formal tests of the relationship between the two variables.

\section{Econometric results}

\subsection{Baseline results}

Our baseline estimates of Eq. (1), using OLS and country fixed effects and the 149 observation datasets, are presented in the first line of panel (a) (for the SCPs) and panel (b) (for the Spring Forecasts) of Table 1. For the SCPs, the $\rho$ estimate is 0.598 (with a t-statistic of 3.650) arising, while that for the Spring Forecasts is 0.565 (with a t-statistic of 3.138). The R-square measure of goodness-of-fit is just over 0.34 in both cases. ${ }^{4}$ The significance and size of these coefficients indicate that forecasters at national and EU level miscalculated the effect of fiscal policy on output growth and to a similar degree. The sign of the $\rho$ coefficient is positive. This means that whereas BL find fiscal multipliers to be underestimated during 2010-2011, the opposite occurred in subsequent years with an over-estimation of the fiscal multiplier arising. The estimated coefficient values indicate that for every one percentage point change in the SBB, the outturn GDP growth rate is about $0.6 \%$ different from that forecast.

\footnotetext{
4 An F-test on the inclusion of the country fixed effects (as reported in the right-hand-side column of the table) rejects the null hypothesis that the country dummies are not different from zero.
} 
(a) SCPs

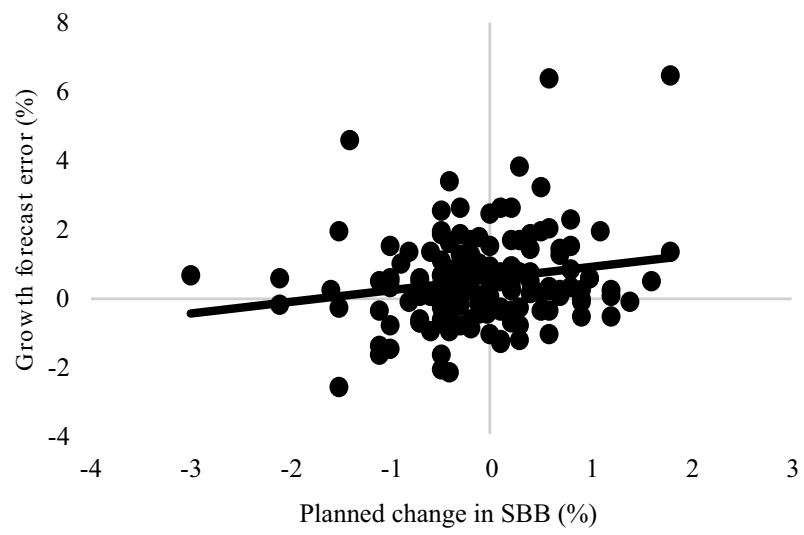

(b) Spring Forecasts

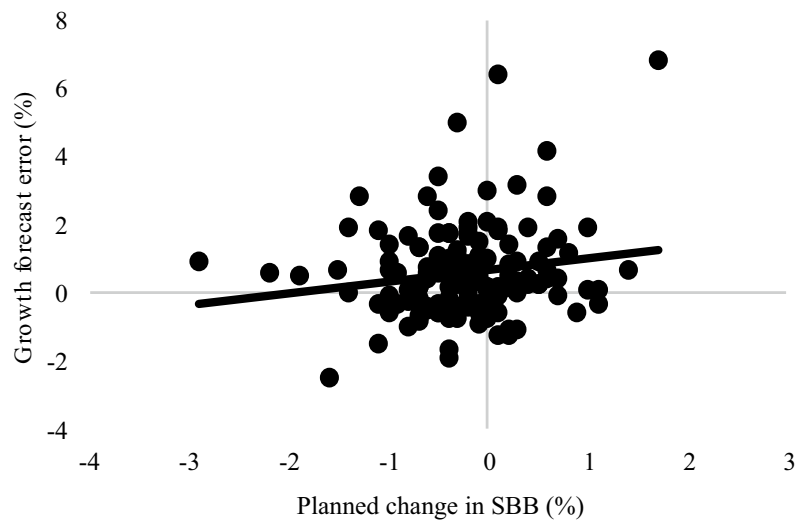

Fig. 1 Growth forecast errors versus planned changes in the SBB in EU member states, 2013-2018

\subsection{Controlling for outliers and member states included}

As per BL, we subject this finding of a significant positive $\rho$ coefficient to a series of robustness tests across Tables 1 and 2. In the first instance, we consider whether the $\rho$ estimate may be sensitive to outliers and report the results in Table 1. Given the potential for significant heteroscedasticity in the regression residuals owing to such observations, a weighted least squares (WLS) estimator is applied to a re-estimation of (1). WLS improves the precision of the estimates by "down-weighting" observations that are known to have a high residual variance. ${ }^{5}$ With this estimation

\footnotetext{
5 The weighting is done by using the residual variances from the initial panel data estimator. See Leamer (2010) and Romano and Wolf (2017) for more on applying weighted least squares.
} 
Table 1 Results of the baseline regression, alternative estimators and different samples

\begin{tabular}{lllll}
\hline & $\mathrm{N}$ & $\begin{array}{l}\rho \\
\text { (T-ratio) }\end{array}$ & R-square & $\begin{array}{l}\text { F-test on fixed } \\
\text { effects }(P \\
\text { values })\end{array}$ \\
\hline a. SCPs & & & \\
Baseline & 149 & $0.598(3.650)$ & 0.341 & 0.002 \\
WLS & 149 & $0.549(6.150)$ & 0.341 & 0.002 \\
Quantile regression & 149 & $0.512(2.846)$ & n.a. & 0.000 \\
All IE and MT excluded & 139 & $0.456(2.726)$ & 0.330 & 0.000 \\
Euro area member states & 100 & $0.697(2.891)$ & 0.375 & 0.002 \\
b. Spring forecast & & & & 0.001 \\
Baseline & 149 & $0.565(3.138)$ & 0.345 & 0.027 \\
WLS & 149 & $0.380(3.165)$ & 0.339 & 0.000 \\
Quantile regression & 149 & $0.444(2.191)$ & n.a. & 0.000 \\
All IE and MT excluded & 139 & $0.400(2.212)$ & 0.35 & 0.002 \\
Euro area member states & 100 & $0.753(2.963)$ & 0.386 & \\
\hline
\end{tabular}

Table 2 Results of the baseline regression, and augmented by control variables

\begin{tabular}{llllll}
\hline & $\mathrm{N}$ & $\begin{array}{l}\rho \\
\text { (T-ratio })\end{array}$ & $\begin{array}{l}\gamma \\
\text { (T-ratio) }\end{array}$ & $\begin{array}{l}\text { R-square } \\
\text { F-test on fixed } \\
\text { effects }(P \\
\text { value })\end{array}$ \\
\hline a. SCPs & & & & & \\
$\quad$ Baseline & 149 & $0.598(3.650)$ & & 0.341 & 0.002 \\
$\quad$ Initial debt ratio & 149 & $0.517(3.104)$ & $0.035(2.017)$ & 0.362 & 0.000 \\
$\quad$ Initial GDP growth rate & 149 & $0.402(2.448)$ & $-0.197(-3.006)$ & 0.387 & 0.000 \\
$\quad$ Initial output gap & 149 & $0.541(3.326)$ & $-0.186(-2.394)$ & 0.371 & 0.000 \\
b. Spring forecast & & & & & 0.345 \\
$\quad$ Baseline & 149 & $0.565(3.138)$ & & 0.001 \\
$\quad$ Initial debt ratio & 149 & $0.497(2.788)$ & $0.042(2.458)$ & 0.376 & 0.000 \\
$\quad$ Initial GDP growth rate & 149 & $0.325(1.700)$ & $-0.199(-3.033)$ & 0.391 & 0.000 \\
Initial output gap & 149 & $0.509(2.840)$ & $-0.165(-2.190)$ & 0.370 & 0.000 \\
\hline
\end{tabular}

method, the SCP and Spring Forecast estimates of $\rho$ are lower, at 0.549 and 0.380 (see Table 1), respectively, but remain highly significant. Another means of addressing outlier values is quantile regression, which differs from OLS in minimising the sum of the squares of the residuals around the median rather than the mean in the estimation process. Table 1 shows it provides estimates of $\rho$ close to those of the WLS estimations.

As well as using alternative regression methods, we also use different samples (with estimation by OLS with country fixed effects) to assess further the finding that fiscal multipliers were overestimated in the post-financial crisis period. In the first instance, we drop all Ireland and Malta observations from the dataset. As well as 
particularly large outlier values in 2015 , those two member states had larger average GDP growth forecast errors than other member states over the 2013 to 2018 period. ${ }^{6}$ The two panels of Table 1 show significant $\rho$ estimates of 0.456 and 0.400 for this smaller sample. We also consider an euro-area-only data sample. In this case, the observations for the non-euro area member states (Bulgaria, Croatia, Czech Republic, Denmark, Hungary, Poland, Romania and Sweden) are dropped, while the 2013 data for Latvia and 2013 and 2014 observations for Lithuania are also excluded as those two member states were not in the euro area in those years. For this sample, the estimates of $\rho$ are above the baseline estimates, at 0.697 and 0.753 .

\subsection{Controlling for other variables}

As well as assessing the influence of outliers, we also control for other variables that could cause changes to fiscal policy and output growth differing from expectation. Consequently, Eq. (1) is augmented as follows:

$$
\text { Forecast Error of } \Delta Y_{i, t}=\alpha+\rho \Delta F_{i, t \mid t}+\gamma C V_{i, t-1 \mid t}+\varepsilon_{i, t}
$$

where $C V_{i, t-1 \mid t}$ refers to the control variable, whose value in year $t-1$ is conditional on the information available on it in year $t$.

The coefficient value on the control variable will indicate whether forecasters failed to capture accurately its influence on the growth rate, and, given the main focus here, on whether the $\rho$ coefficient estimate is sensitive to it. The tables in SCPs capture member states' estimates of a number of relevant control variables and so those, and, in turn, the corresponding entries in the Spring Forecasts, are employed here. The coefficient values in Table 2 are from a regression estimation of Eq. (2) by OLS with country fixed effects. The baseline estimates of $\rho$ from Table 1 are shown in the initial row of Table 2. The variables shown in the first column of Table 2 are the control variables that are included in turn alongside $\Delta F_{i, t \mid t}$ in the regressions.

The first control variable used is the General Government debt ratio for the past year $(t-1)$ contained in the SCP/Spring Forecast tables, marked as "Initial [i.e. $t-1$ ] debt ratio" in Table 2. The coefficient on this variable is 0.035 and 0.042 for the SCP and Spring Forecast samples, respectively, and is statistically significant, indicating that forecasters failed to capture this variable's influence on output growth accurately. The positive $\gamma$ coefficient values in this case indicate that the government debt ratio's influence on GDP growth forecasts is unduly pessimistic and the higher the initial debt ratio the larger the positive growth rate forecast error that arises. ${ }^{7}$

\footnotetext{
${ }^{6}$ Excluding 2015, the average growth forecast errors for Ireland and Malta over the years 2013-2018 were $2.3 \%$ and $2.8 \%$, respectively, for the SCP data and $2.5 \%$ and $2.9 \%$ for the Spring Forecast data. For the other 24 member states, the average growth forecast errors were $0.4 \%$ for the SCPs and $0.5 \%$ for the Spring Forecasts.

${ }^{7}$ For the SCP panel, the average initial General Government debt-to-GDP ratio is $65.5 \%$, with a range of values from 9 to $132.7 \%$. For the Spring Forecast panel, the corresponding entries are $65.4 \%, 9 \%$, and $132.7 \%$.
} 
Two control variables reflecting output conditions in the economy-the initial GDP growth rate and the initial output gap —are also considered. Table 2 shows these variables each have negative, significant coefficients. ${ }^{8}$ A positive (negative) initial GDP growth rate then leads forecasters to overestimate (underestimate) output growth rates in the current year, ceteris paribus. Similarly, a positive (negative) output gap also leads to a forecast GDP growth rate that is greater (less) than the observed outturn.

These results then indicate that during the 2013-2018 period both member states and the European Commission did not account satisfactorily for the effects of initial fiscal and output conditions on the projected GDP growth rate in year $t$ at the time of forecasting. Throughout these regressions, the estimated $\rho$ coefficient is statistically significant at conventional levels and ranges in value between 0.402 and 0.541 for the SCP data and 0.325 and 0.509 for the Spring Forecasts data.

\section{Conclusion}

Blanchard and Leigh $(2013,2014)$ find forecasters underestimating the effects of budgetary policy on output growth in the EU during the deep euro area recession of the early 2010s. Our results indicate that, notwithstanding the lessons of the crisis and the EU fiscal and forecasting reforms that occurred in response, ex-ante multipliers are misestimated in the post-crisis period. While BL found fiscal multipliers to be underestimated during 2010-11, we find them to be overestimated in later years. Forecasters are therefore still not capturing accurately the impact of fiscal policy on output growth.

Empirical studies of fiscal multipliers find substantial variation in their values across countries and different stages of the economic cycle. Auerbach and Gorodnichenko (2012), for instance, find US fiscal multipliers fluctuating from close to zero in normal times up to 2.5 during recessions. BL contend that if "normal times" multipliers are used in assessing the effects of fiscal retrenchment in a severe downturn then growth forecast errors should be systematically correlated with changes in the stance of fiscal policy, a hypothesis supported by their empirical work. What our contribution shows is that this systematic relationship between growth forecast errors and fiscal policy has persisted in the more 'normal' years after the 2008-2012 crisis period, albeit with an opposite sign and against a background of institutional reforms enacted in part to improve forecasting in the EU. ${ }^{9},{ }^{10}$ Forecasters appear to have moved from

\footnotetext{
8 In the SCP panel, the average initial GDP growth rate was 2\%, with 127 of the 149 observations having a positive growth rate. The average initial output gap was $-1.2 \%$ with most observations (117 out of 149) having a negative value. For the Spring Forecast panel, the averages GDP growth rate is $2 \%$ with 127 of the 149 observations having a positive value. The average output gap is $-1.2 \%$ with 116 negative output gap observations.

9 GDP growth rate outturns averaged $2.7 \%$ in the 149 -observation dataset used here.

10 Blanchard and Leigh (2014, p. 195) also applied their methodology to the pre-crisis period of 19972008 and find no evidence of fiscal multipliers being under- or overestimated "during these more normal times".
} 
underestimating the effect of fiscal policy on output growth in the downturn of the early 2010 s to overestimating it subsequently.

The empirical analysis in the paper drew on two forecast sets, those of member states in the SCPs and those of the European Commission in the Spring Forecasts. A lack of substantial differences in forecasting accuracy across institutions is quite common in the literature (see, for example, Dohrn \& Schmidt, 2011). This is backed up here by the similarity of the results between the member states and the Commission. It also suggests that the findings of Von Hagen (2010) and Merola and Perez (2013) — that the reliance of supra-national organisations on national governments for country information may cause those bodies to absorb the biases of the member states - may still hold.

On a concluding and topical note, the Covid-19 pandemic presents a similar economic environment to European economies as arose during the early 2010s recession, with a large, sharp contraction of $7.5 \%$ in euro area GDP expected in 2020 (IMF, 2020b). Unlike the recession of the early 2010s, European governments are offsetting this contraction through fiscal stimulus. Notwithstanding the different policy response to the economic shock on this occasion and our dataset covering a period of more benign circumstances, our central result of official appraisals of the effect of planned fiscal policy on output growth in the EU being inaccurate in recent years should have a particular resonance. While fiscal multipliers will tend to be state-dependent, our findings indicate that forecasters in the EU continue to have difficulty estimating the size of multipliers and this may affect their assessments of the impact of fiscal policy now in train.

Acknowledgement The views expressed here are those of the authors and not necessarily those of the Central Bank, the ESRI or the European System of Central Banks.

\section{References}

Auerbach, A., \& Gorodnichenko, Y. (2012). Measuring the output responses to fiscal policy. American Economic Journal Economic Policy, 4(2), 1-27.

Blanchard, O., \& Leigh, D. (2013). Growth forecast errors and fiscal multipliers. American Economic Review, 103(3), 117-120.

Blanchard, O., \& Leigh, D. (2014). Learning about fiscal multipliers from growth forecast errors. IMF Economic Review, 62(2), 179-212.

Christian Aid (2017). Impossible structures: Tax outcomes overlooked by the 2015 tax spillover analysis. Christian Aid Report Part Two.

Dohrn, R., \& Schmidt, C. (2011). Information or institution? On the determinants of forecast accuracy. Journal of Economics and Statistics (Jahrbuecher fuer Nationaloekonomie und Statistik), 231(1), 9-27.

FitzGerald, J. (2018). National accounts for a global economy: The case of Ireland. Special article, Quarterly Economic Commentary, June, Economic and Social Research Institute, Dublin.

Frankel, J. (2011). Over-optimism in forecasts by official budget agencies and its implications. Oxford Review of Economic Policy, 27(4), 536-562.

Frankel, J., \& Schreger, J. (2013). Over-optimistic official forecasts and fiscal rules in the Eurozone. Review of World Economics (Weltwirtschftliches Archiv), 149(2), 247-272.

International Monetary Fund (2020a). Fiscal Monitor, Chapter 1, April 2020.

International Monetary Fund (2020b). World Economic Outlook, April 2020.

Jonung, L., \& Larch, M. (2006). Improving fiscal policy in the EU: The case for independent forecasts. Economic Policy, 21, 491-534.

Leamer, E. E. (2010). Tantalus on the road to asymptotia. Journal of Economic Perspectives, 24(2), 31-46.

Merola, R., \& Perez, J. (2013). Fiscal forecast errors: Governments versus independent agencies. European Journal of Political Economy, 32, 285-299. 
Romano, J., \& Wolf, M. (2017). Resurrecting weighted least squares. Journal of Econometrics, 197(1), 1-19. Spilimbergo, A., Symansky, S., \& M. Schindler (2009). Fiscal multipliers. IMF Staff Position Note SPN/09/11.

Von Hagen, J. (2010). Sticking to fiscal plans: The role of institutions. Public Choice, 144(3), 487-503.

Publisher's Note Springer Nature remains neutral with regard to jurisdictional claims in published maps and institutional affiliations. 